DOI: $10.17805 /$ zpu.2019.1.8

\title{
Практика первичной профессиональной социализации выпускников школ - потенциальных абитуриентов вуза медицинского профиля
}

\author{
И. И. КОРЯГИНА, Н. В. КУРЫЛЕВА \\ ИВАНОВСКАЯ ГОСУДАРСТВЕННАЯ МЕДИЦИНСКАЯ АКАДЕМИЯ \\ МИНИСТЕРСТВА ЗДРАВООХРАНЕНИЯ РОССИЙСКОЙ ФЕДЕРАЦИИ
}

В статье обоснована и проанализирована практика профессиональной социализации выпускников школ - потенциальных абитуриентов вуза медицинского профиля в триаде «преподаватель - обучающийся - выпускник / потенциальный абитуриент» в профориентационных мероприятиях. Обозначены основные направления результативной работы с потенциальными абитуриентами в регионах и мероприятиях вузовского уровня. Организовано взаимодействие в системе на основании беседы, анкетирования, просмотра видеоматериалов, психодиагностики, разработки конкретных практических рекомендаций, направляющих познавательные потребности обучающихся. Созданы психолого-педагогические условия для первичной профессиональной ориентации и социализации учащихся школ.

Ключевые слова: профессиональная социализация; профориентационная работа; системный подход; триада; медицинский вуз

\section{ВВЕАЕНИЕ}

И сследования профессиональной социализации специалистов получили большое развитие в психологии, педагогике, социологии. Изучение взаимодействия профессии и личности является общепринятым в отечественной психологии (Климов, 2010). Профессиональное становление исследовалось В.А. Шадриковым, Т. В. Кудрявцевым, К. А. Абульхановой-Славской, Ю. П. Поваренковым, Е. А. Климовым и другими учеными. Ю. П. Поваренков доказывает, что профессионализация как форма социализации и индивидуализации личности охватывает разные этапы профессионального пути, начиная с профессионального определения (Поваренков, 2002). Е. И. Головаха указывает на то, что с выбором жизненного и профессионального пути человек сталкивается в том возрасте, когда он может не до конца осознавать все отдаленные последствия принятых в юности решений (Головаха, 1998). И. М. Ильинский приводит анализ развития и формирования личности (писателя И. А. Бунина), достигшей высокого уровня развития в профессии, продуктивной, творческой, под воздействием системы факторов - социальных, семейных, интрапсихических (Ильинский, 2018).

Б. А. Ясько указывает на то, что профессиональное развитие врача имеет социально фиксированные модули профессионализации. Первый модуль - стадия довузовской подготовки - состоит в завершении базового образования и профессиональной ориентация в избранной сфере труда. Переход на второй модуль обусловлен выбором образа субъекта врачебного труда в студенческий период и формированием профессионально важных качеств, определяющих создание профессиональной «Я-концепции». Третий модуль - это послевузовский этап, когда выбирается предмет труда, исходя из социальной востребованности, и нередко делается выбор того предмета труда, который идентифицируется с личностными качествами. Четвертый модуль реализуется на стадии упрочения карьеры и отражается в принятии ответственных решений и выполнении профессиональных специальных действий (Кагитина, 2008). 
Исследование Ю. П. Поваренкова в качестве основного механизма профессионализации студентов определяет социальную ситуацию профессионального развития в двух периодах - учебно-академическом (1-3-й курсы обучения) и учебно-профессиональном (4-5-й курсы). Эти периоды принципиально отличаются друг от друга и приводят к скачкообразному ходу профессионализации студентов (Поваренков, 2002).

В. Г. Маралов и В. А. Ситаров указывают на то, что дичность специалиста, в силу условий профессиональной деятельности непрерывно взаимодействующая с людьми, формируется в процессе обучения в вузе (Маралов, Ситаров, 2018).

В этой связи реализация мероприятий по первичной профессиональной социализации выпускников школ - потенциальных абитуриентов медицинского вуза на этапе довузовской подготовки является актуальной и практико-ориентированной проблемой.

\section{ОБЗОР НАУЧНОЙ АИТЕРАТУРЫ}

Профессиональная социализация изучалась Г. С. Абрамовой, А. Ф. Амировой, А. Н. Глушко, Н. А. Аакосиной, Ю. П. Аисицыной, В. А. Назифуллиной, Н. А. Твороговой, Б. А. Ясько, Е. С. Полат. Результативность первичной профессиональной социализации путем создания условий, учета многообразия факторов, обеспечивающих успешную интеграцию обучающегося в профессиональную среду, рассматривается в работах $\Lambda$. В. Мурзагалиной (Мурзагалина, 2010).

Профессиональная социализация врачей дифференцируется на первичную, вторичную и компетентностную. Первичная профессиональная социализация характеризуется тем, что, наряду с другими важными профессиональными и социальными качествами, в этот период формируется ценностно-мировоззренческая позиция будущего врача, значимость которой в свете происходящих социальных преобразований в обществе чрезвычайно высока. По мнению $\Lambda$. В. Мурзагалиной, профессиональная социализация является важным фактором воспроизводства медицинских кадров, реализуется в субъект-субъектной форме и направлена на активизацию социальной и профессиональной мобильности. В настоящее время проводимые в России образовательные реформы носят этапный характер и сопровождают все уровни системы образования РФ. Выполнение требований федеральных государственных образовательных стандартов основного общего образования, среднего (полного) общего образования ориентируют школу на становление таких личностных характеристик выпускника - потенциального абитуриента, как ориентирующийся в мире профессий, понимающий значение профессиональной деятельности для человека в интересах устойчивого развития общества и природы; подготовленный к осознанному выбору профессии и др. (Приказ Министерства образования и науки РФ от 17 мая 2012 г. № 413).

Ранее в наших публикациях приводился опыт результативного управления воспитательной деятельностью обучающихся вуза медицинского профиля на разных этапах их профессионального онтогенеза, основанный на ценностях гуманных отношений между педагогами и обучающимися (Курылева, 2017; Корягина, 2017).

Перед школами и вузами стоит сложная задача по организации профориентационной работы учащихся, нацеленной на первичную социализацию выпускников школ. Вуз заинтересован в приеме студентов, мотивированных на подготовку по выбранной специальности. Следует заметить, что профориентация - объемное понятие. Н. А. Митина пишет: «...профессиональная ориентация (от фран. orientation установка) - комплекс психолого-педагогических мероприятий, направленных на 
оптимизацию процесса трудоустройства молодежи в соответствии с желаниями, склонностями и сформировавшимися способностями и с учетом потребности в специалистах народного хозяйства и общества в целом» (Митина, 2014: 1037).

А. А. Сазонов и другие определяют профессиональную ориентацию как деятельность по подготовке молодежи к выбору профессии, а социально-профессиональную ориентацию характеризуют как подготовку молодежи к выбору профессии и своего места в обществе (Сазонов, Калугин, Меньшиков, 2009). Н. С. Пряжников выделяет следующие направления в профориентации: профинформация, профагитация, профпросвещение, профдиагностика (профотбор, профподбор) и профконсультация (Пряжников, 2002). Профориентация на стадии профессионального самоопределения является актуальным направлением работы с обучающимися. Е. А. Климов выделяет два уровня профессионального самоопределения: 1) гностический (перестройка сознания и самосознания); 2) практический уровень (реальные изменения социального статуса человека) (Климов, 2010).

Социализацию учащейся молодежи на базе эмпирических исследований в контексте переживаемых трудностей подробно анализирует А. И. Ковалева (Ковалева, 1996). Она рассматривает и обосновывает социализационную траекторию как интегральный показатель характера и направленности социализации, отражая ее объективную и субъективную стороны. С ее точки зрения, социализационная траектория родственна понятию «жизненный путь» и отражает историю формирования и развития личности по событиям, кардинально повлиявшим на жизнедеятельность данного индивида (Ковалева, 2012).

К наиболее распространенным методам профориентационной социализации относят информационно-справочные, просветительские методы; методы профессиональной психодиагностики; методы морально-эмоциональной поддержки участников профориентации, методы оказания помощи в конкретном выборе и принятии решения (Карушева, Севостьянова, 2016). Н. С. Пряжников выделяет две группы методов профориентационной работы:

1) научно-практические, которые условно можно разделить на информационносправочные, диагностические, активизирующие, методы морально-эмоциональной поддержки клиента, принятия профконсультационного решения и организационные методы;

2) научно-исследовательские, которые условно подразделяются на проектировочные, методы сбора информации, обработки результатов, интерпретации полученных результатов, построения умозаключений и выводов (Пряжников, 2002: 37).

Г. 3. Ефимова указывает на то, что реализация мероприятий по первичной профессиональной социализации с абитуриентами способствует адекватному восприятию профессии, ее осознанному выбору (Ефимова, 2014: Электронный ресурс).

\section{ОПЫТ ИССАЕАОВАНИЯ В ИВАНОВСКОЙ ГОСУААРСТВЕННОЙ МЕАИЦИНСКОЙ АКААЕМИИ}

Первичная профессиональная социализация осуществляется через учебно-воспитательный процесс, внеурочную и внешкольную работу с учащимися.

Профессиональная социализация обучающихся медицинского вуза носит системный характер: преподавателями организуются занятия со школьниками профильных классов; на факультете довузовской подготовки организовано обучение в очной и в заочной формах (по биологии, химии, русскому языку) для подготовки школьни- 
ков к сдаче ЕГЭ. Студенты совместно со школьниками проводят научные исследования, результаты которых ежегодно докладываются в рамках конференций.

В 2017 г. под руководством И. И. Корягиной и Н. В. Курылевой в Ивановской государственной медицинской академии, в вузовском Центре менеджмента качества, профориентационной школе «Наша смена» при участии Совета студентов была проведена работа по первичной профессиональной социализации выпускников школ. В том числе изучались вопросы влияния, изменения восприятия профессии врача выпускниками, осознанности выбора данной профессии; оценки карьерных перспектив; условий, при которых в полной мере в соответствии с индивидуально-типологическими свойствами личности потенциальные абитуриенты могли бы приобретать первоначальный профессиональный опыт и необходимые профессионально-личностные качества.

Аля этого осуществлялись мероприятия, в число которых входили презентация медицинского вуза как образовательного учреждения, отвечающего современным требованиям; информирование обучающихся об особенностях обучения на лечебном, педиатрическом и стоматологическом факультетах - для повышения интереса к академии потенциальных абитуриентов как в Ивановской области, так и за ее пределами, а также повышения конкурентоспособности; работа школы профессиональной ориентации «Наша смена» для старшеклассников.

В течение двух семестров школьники, планирующие поступление в вуз, знакомились на кафедрах с дисциплинами, ожидающими их на младших курсах: гистологией, эмбриологией, анатомией, экстремальной медициной. Занятия проходили в Центре практической подготовки, где ребята знакомились с выполнением медицинских манипуляций.

Завершающим штрихом, своеобразным әкзаменом для учащихся «Нашей смены» являлась возможность участия в научной студенческой конференции. Старшеклассники представляли свои первые исследования, в выполнении которых им помогали студенты. Выпускники школ - потенциальные абитуриенты могли прояснить для себя вопросы профессиональной ориентации и более реально наметить цели на свое профессиональное будущее.

В рамках проекта осуществлялись мероприятия по первичной профессиональной социализации со старшеклассниками Вологодской, Тульской, Московской, Ивановской, Владимирской областей, еще только рассматривающих возможность поступления в медицинский вуз. Работа организовывалась в триаде «преподаватель - обучающийся - выпускник / потенциальный абитуриент» и предусматривала участие в ежегодном Ане открытых дверей.

Изучение требований абитуриентов к академии в 2017 г. проводилось в два этапа. В процессе работы в школах учащиеся просматривали видеоматериалы (ролик) о медицинском вузе, взаимодействовали со студентами академии - на все заданные вопросы студенты давали исчерпывающие ответы, заполняли анкеты (первый этап проекта). По результатам опроса 78 респондентов был сформирован банк электронных адресов абитуриентов, позволяющий оценить эффективность проекта по результату присутствия старшеклассников на Ане абитуриента. Аанные анкетирования, беседы показали, что $32 \%$ выпускников школ, не имевших ранее цель поступить в медицинский вуз, в качестве приоритетной выбрали профессию врача.

На втором этапе проекта, 2 апреля 2017 г., в академии состоялся Аень открытых дверей. На мероприятии присутствовали учащиеся из девяти регионов России: Ивановской области, Владимирской, Московской, Костромской, Нижегородской, Яро- 
славской, Вологодской, Брянской, Рязанской областей. Абитуриентам (213 чел.) предлагалось пройти психологические тесты, определиться с выбором профессионального жизненного пути, объективно взвесив свои желания и реальные возможности, познакомиться с медицинскими процедурами, а также принять участие в анкетировании. Методики для психологического тестирования были подготовлены студентами первого курса под руководством преподавателей в рамках изучения дисциплины «Психология и педагогика». В Аень абитуриента студентам представилась возможность апробации подобранных методик. Совет студентов (преимущественно старшекурсники) под руководством преподавателей для осуществления преемственности и повышения результативности мероприятий по первичной профессиональной социализации провел в регионах и непосредственно в рамках мероприятия Аня абитуриента анкетирование 456 абитуриентов.

Анализируя требования, в соответствии с которыми абитуриентом осуществляется выбор медицинского вуза, можно заключить, что доминирующими на протяжении всего периода обучения в 11-м классе являются следующие критерии выбора: престиж профессии врача и медицинского вуза (от 56 до $60 \%$ респондентов); квалификация преподавателей (от 60,2 до 52,7\%;); хорошие условия для занятий (от 52,5 до 54,5\%); возможность выполнения трудовой функции по полученной в рамках обучения специальности $(69,2 \%)$. При приближении сдачи ЕГЭ приоритетными становятся проходной балл, позволяющий поступить в вуз (30,9\% респондентов), и отсутствие коррупции $(27,2 \%)$.

Основными источниками получения абитуриентами информации о медицинских вузах в течение завершающего года обучения в школе являются сайты образовательных учреждений (до 81\%); мнение студентов, обучающихся в данном вузе, знакомых, друзей $(69,2 \%)$; информация, полученная на Ане открытых дверей (с $37,1 \%$ в начале года до $69 \%$ к концу учебного года).

Показатели ранжирования подтверждают достоверность процентного соотношения требований абитуриентов к вузу.

Старшеклассники отмечают такие факторы, определяющие выбор образовательного учреждения, как высокий уровень профессиональной практической подготовки, возможность участия в научно-исследовательской работе во время обучения. Вызывает интерес то, что на выбор вуза не оказывает влияния территориальный признак (у 17,9 и $7,2 \%$ опрошенных - на первом и втором этапах соответственно) и семейные традиции $(17,9$ и 9,7\%). Среди предложенных вузов, по данным опросов, Ивановская государственная медицинская академия Министерства здравоохранения Российской Федерации (которую выбрали 71,7 и $100 \%$ опрошенных на первом и втором этапах соответственно) соперничает с Ярославским государственным медицинским университетом Министерства здравоохранения Российской Федерации (38,4 и 49\%), Первый Московский государственный медицинский университет имени И. М. Сеченова Министерства зАравоохранения Российской Федерации (48,7 и 36,3\%), Российский национальный исследовательский медицинский университет имени Н. И. Пирогова Министерства зАравоохранения Российской Федерации (41 и 32,7\%).

\section{ЗАКАЮЧЕНИЕ}

Результаты, полученные в ходе работ по первичной профессиональной социализации, являются значимыми для руководства вуза медицинского профиля, так как обеспечивают возможность оперативно реагировать на потребности абитуриентов и, как 
следствие, повышать конкурентоспособность образовательного учреждения. Согласно полученным данным, работу с выпускниками школ следует проводить по двум основным направлениям: очное общение с обучающимися школ в регионах, демонстрация видеоматериалов, удовлетворяющих познавательные потребности учащихся, размещение востребованной для них информации на сайте вуза, привлечение учащихся к посещению школы «Наша смена», где происходит интеграция в профессиональную деятельность врача и в целом в социокультурную среду медицинского вуза.

На основании результатов исследований сформулированы следующие практические рекомендации:

1) активизировать профориентационные и имиджевые мероприятия вуза в регионах;

2) своевременно обновлять информацию на сайте:

- провести анализ наполняемости контента сайта по кафедрам, так как информация о мероприятиях отражается в новостном разделе, затем помещается в архивный, что затрудняет поиск абитуриентами востребованной для них информации;

- на страницах кафедр подробно информировать о квалификации, достижениях преподавателей кафедры и студентов;

- отслеживать/модерировать социальные сети;

- конкретизировать, более детально и предметно освещать условия обучения, вопросы практической подготовки обучающихся, перечень практических навыков и баз практик;

— информировать об антикоррупционных мероприятиях, проводимых вузом.

\section{СПИСОК АИТЕРАТУРЫ}

Головаха, Е. И. (1998) Жизненная перспектива и профессиональное самоопределение молодежи. Киев : Наукова думка. 143 с.

Ефимова, Г. 3. (2014) Первичная профессиональная социализация студентов направления «Социология» учреждений высшего профессионального образования» [Электронный ресурс]// Науковедение. Выпуск 6 (25), ноябрь - декабрь. URL: https://naukovedenie.ru/PDF/43PVN614.pdf (дата обращения: 26.08.2018). DOI: 10.15862/43PVN614

Ильинский, И. М. (2018) Не божий дар, а феномен природы // Знание. Понимание. Умение. № 1. С. 5-27. DOI: $10.17805 /$ zpu.2018.1.1

Кагитина, И. В. (2008) Профессиональная социализация студентов медицинских вузов : автореф. дис. ... канд. социол. наук. Волгоград. 28 с.

Карушева А. В., Севостьянова Е. П. (2016) Особенности профессиональной ориентации старшеклассников в условиях общеобразовательных учреждений // Молодой ученый. № 4. C. 687-691.

Климов, Е. А. (2010) Психология профессионального самоопределения. М. : Издательский центр «Академия». 304 с.

Ковалева, А. И. (1996) Социализация личности: норма и отклонение. М. : Институт молодежи. 224 с.

Ковалева, А. И. (2012) Методологические проблемы исследования социализации // Знание. Понимание. Умение. № 2. С. 19-24.

Корягина, И. И. (2017) Развитие гуманных отношений между детьми и взрослыми в воспитательном процессе // Высшее образование для XXI века: проблемы воспитания : доклады и материалы XIV Международной научной конференции : в 2 ч. : сборник трудов конференции / под ред. И. М. Ильинского. М. : Изд-во Московского гуманитарного университета. 622 с. С. 3-11.

Курылева, Н. В. (2017) Психолого-педагогические аспекты организации воспитательной деятельности в медицинском вузе // Высшее образование для XXI века: проблемы воспитания : доклады и материалы XIV Международной научной конференции : в 2 ч. : сборник трудов кон- 
ференции / под ред. И. М. Ильинского. М. : ИзА-во Московского гуманитарного университета. 622 c. C. $40-44$.

Маралов, В. Г., Ситаров, В. А. (2018) Разработка диагностического опросника по выявлению позиций взаимодействия у студентов - будущих специалистов сферы психолого-педагогического сопровождения // Знание. Понимание. Умение. № 1. С. 167-177. DOI: 10.17805/zpu.2018.1.13

Митина, Н. А. (2014) Система профессиональной ориентации молодежи на педагогические специальности // Молодой ученый. № 4. С. 1037-1040.

Мурзагалина, $\Lambda$. В. (2010) Первичная профессиональная социализация будущих врачей на этапе обучения в вузе : автореф. дис. ... канд. пед. наук. Уфа. 27 с.

Поваренков, Ю. П. (2002) Психологическое содержание профессионального становления человека. Томск : Издательство Национального исследовательского Томского государственного университета. $160 \mathrm{c}$.

Полат, Е. С. (2000) Новые педагогические и информационные технологии в системе образования. М. : Академия. 211 с.

Пряжников, Н. С. (2002) Методы активизации личностного и профессионального самоопределения. М. : НПО «Модэк». 392 с.

Сазонов, А. А., Калугин, Н. И., Меньшиков, А. П. (2009) Профессиональная ориентация молодежи. М. : Высшая школа. 272 с.

Lата поступления: 27.08.2018г.

\section{PRACTICE OF PRIMARY PROFESSIONAL SOCIALIZATION OF SCHOOL LEAVERS- POTENTIAL MEDICAL UNIVERSITY ENTRANTS \\ I. I. KORYAGINA, N. V. KURYLEVA \\ ivanovo State Medical Academy, Ministry of Health of the Russian Federation}

The paper substantiates and analyzes the practice of professional socialization of school leavers potential medical university entrants in the triad «teacher - student - graduate/potential entrant» in vocational activities. It outlines the main directions of effective work with potential entrants in the regions and activities at the university level. The authors organized interaction in the system based on conversation, questionnaires, watching video materials, psychodiagnostics, development of specific practical recommendations, directing the cognitive needs of students. Psychological and pedagogical conditions have been created for primary vocational guidance and socialization of school students.

Keywords: professional socialization; vocational work; system approach; triad; medical university

\section{REFERENCES}

Golovakha, E. I. (1998) Zbiznennaia perspektiva i professional' noe samoopredelenie molodezhi. Kiev, Naukova dumka. 143 p. (In Russ.).

Efimova, G. Z. (2014) Pervichnaia professional'naia sotsializatsiia studentov napravleniia «Sotsiologiia» uchrezhdenii vysshego professional'nogo obrazovaniia». Naukovedenie. Vol. 6 (25), November - December [online] Available at: https://naukovedenie.ru/PDF/43PVN614.pdf (accessed 26.08.2018). DOI: 10.15862/43PVN614 (In Russ.).

Il'inskii, I. M. (2018) Ne bozhii dar, a fenomen prirody. Znanie. Ponimanie. Umenie, no. 1, pp. 5-27. DOI: 10.17805/zpu.2018.1.1 (In Russ.).

Kagitina, I. V. (2008) Professional' naia sotsializatsiia studentov meditsinskikb vuzov: Thesis of Dis. ... Candidate of Sociology. Volgograd. 28 p. (In Russ.).

Karusheva A. V. and Sevost'ianova E. P. (2016) Osobennosti professional'noi orientatsii starsheklassnikov v usloviiakh obshcheobrazovatel'nykh uchrezhdenii. Molodoi uchenyi, no. 4, pp. 687-691. (In Russ.).

Klimov, E. A. (2010) Psikbologiia professional'nogo samoopredeleniia. Moscow, Izdatel'skii tsentr «Akademiia». 304 p. (In Russ.).

Kovaleva, A. I. (1996) Sotsializatsiia lichnosti: norma i otklonenie. Moscow, Institut molodezhi. 224 p. (In Russ.). 
Kovaleva, A. I. (2012) Metodologicheskie problemy issledovaniia sotsializatsii. Znanie. Ponimanie. Umenie, no. 2, pp. 19-24. (In Russ.).

Koriagina, I. I. (2017) Razvitie gumannykh otnoshenii mezhdu det'mi i vzroslymi v vospitatel'nom protsesse. In: Vysshee obrazovanie dlia XXI veka: problemy vospitaniia : doklady i materialy XIV Mezhdunarodnoi nauchnoi konferentsii : in 2 vol. / ed. by I. M. Il'inskii. Moscow, Izd-vo Moskovskogo gumanitarnogo universiteta. 622 p. Pp. 3-11. (In Russ.).

Kuryleva, N. V. (2017) Psikhologo-pedagogicheskie aspekty organizatsii vospitatel'noi deiatel'nosti v meditsinskom vuze. In: Vysshee obrazovanie dlia XXI veka: problemy vospitaniia : doklady i materialy XIV Mezhdunarodnoi nauchnoi konferentsii : in 2 vol. / ed. by I. M. Il'inskii. Moscow, Izd-vo Moskovskogo gumanitarnogo universiteta. 622 p. Pp. 40-44. (In Russ.).

Maralov, V. G. and Sitarov, V. A. (2018) Razrabotka diagnosticheskogo oprosnika po vyiavleniiu pozitsii vzaimodeistviia u studentov - budushchikh spetsialistov sfery psikhologo-pedagogicheskogo soprovozhdeniia. Znanie. Ponimanie. Umenie, no. 1, pp. 167-177. DOI: 10.17805/zpu.2018.1.13 (In Russ.).

Mitina, N. A. (2014) Sistema professional'noi orientatsii molodezhi na pedagogicheskie spetsial'nosti. Molodoi uchenyi, no. 4, pp. 1037-1040. (In Russ.).

Murzagalina, L. V. (2010) Pervichnaia professional' naia sotsializatsiia budushchikb vrachei na etape obucheniia v vuze: Thesis of Diss. ... Candidate of Pedagogy. Ufa. 27 p. (In Russ.).

Povarenkov, Iu. P. (2002) Psikbologicheskoe soderzhanie professional'nogo stanovleniia cheloveka. Tomsk, Izdatel'stvo Natsional'nogo issledovatel'skogo Tomskogo gosudarstvennogo universiteta. 160 p. (In Russ.).

Polat, E. S. (2000) Novye pedagogicheskie i informatsionnye tekbnologii v sisteme obrazovaniia. Moscow, Akademiia. 211 p. (In Russ.).

Priazhnikov, N. S. (2002) Metody aktivizatsii lichnostnogo i professional'nogo samoopredeleniia. Moscow, NPO «Modek». 392 p. (In Russ.).

Sazonov, A. D., Kalugin, N. I. and Men'shikov, A. P. (2009) Professional' naia orientatsiia molodezhi. Moscow, Vysshaia shkola. 272 p. (In Russ.).

Submission date: 27.08 .2018$.

Корягина Ирина Ивановна - кандидат педагогических наук, помощник ректора по качеству, доцент кафедры психологии и педагогики Ивановской государственной медицинской академии Министерства здравоохранения Российской Федерации. Адрес: 153012, Россия, г. Иваново, Шереметевский пр-т, д. 8. Тел.: +7 (4932) 41-77-94. Эл. адрес: koryaginairina@mail.ru

Курылева Наталья Владимировна — кандидат психологических наук, доцент кафедры гуманитарных наук, заместитель начальника Центра качества Ивановской государственной медицинской академии Министерства здравоохранения Российской Федерации. Адрес: 153012, Россия, г. Иваново, Шереметевский пр-т, д. 8. Тел.: +7 (902) 316-37-12. Эл. aдpec: nk-1009@mail.ru

Koryagina Irina Ivanovna, Candidate of Pedagogy, Assistant Rector for Quality, Associate Professor, Department of Pedagogy and Psychology, Ivanovo State Medical Academy, Ministry of Health of the Russian Federation. Postal address: 8, Sheremetevsky Ave., Ivanovo, Russian Federation, 153012. Tel.: +7 (4932) 41-77-94. E-mail: koryaginairina@mail.ru

Kuryleva Natalya Vladimirovna, Candidate of Psychology, Associate Professor, Department of the Humanities, Deputy Head, Center of Quality, Ivanovo State Medical Academy, Ministry of Health of the Russian Federation. Postal address: 8, Sheremetevsky Ave., Ivanovo, Russian Federation, 153012. Tel.: +7 (902) 316-37-12.E-mail:nk-1009@mail.ru 